Conclusion: The prevalence of neurodevelopmental abnormalities in children born to mothers with SLE or APS seems to be higher than normal population and more educational attention is important in these children, and need longterm follow-up.

Disclosure of Interests: None declared

DOI: 10.1136/annrheumdis-2020-eular.240

\section{THU0269 $\quad$ CLINICAL COMPARISON OF NEW CRITERIA FOR SYSTEMIC LUPUS ERYTHEMATOSUS IN A COLOMBIAN COHORT}

S. Herrera $^{1}$, J. C. Diaz-Coronado ${ }^{1,2}$, D. Hernandez-Parra ${ }^{1}$, Y. DurangoDurango $^{1}$, C. Perez-Rios ${ }^{1}$, M. Posada-Velásquez ${ }^{1}$, J. Rojas-Londoño ${ }^{1}$, M. Vallejo-Patiño ${ }^{1}$, K. Marín ${ }^{1}$, C. Guerrero-Calderón ${ }^{1}$, S. Jaramillo ${ }^{1}$, V. UsugaGraciano $^{1}$, M. I. López-Flórez ${ }^{1}$, C. Restrepo-Raigosa ${ }^{1}$, J. P. Restrepo-Hincapié ${ }^{1}$ C. Carvajal-Naranjo ${ }^{1}$, S. Restrepo-Upegui ${ }^{1}$, R. Pineda Tamayo ${ }^{1} .{ }^{1}$ Artmedica IPS, Grupo de Información Clínica, Medellín, Colombia; ${ }^{2}$ CES University, Departamento Medicina Interna, Medellín, Colombia

Background: Due to heterogeneity of the disease, there has been several classification criteria for Systemic Lupus Erythematosus (SLE). These have considered the knowledge obtained through the years and have strived for increased sensibility and specificity. Recently, both EULAR and ACR have proposed new criteria for disease classification that mandate a positive ANA result to apply the criteria.

Objectives: To compare the 2019 EULAR/ACR classification criteria (1) with the Systemic Lupus International Collaborating Clinics (SLICC) 2012 classification criteria (2) and the American College of Rheumatology (ACR) 1997 classification criteria in a Colombian cohort (3).

Methods: A cross-section retrospective study was done with data collected between 2014 and 2018 from a population diagnosed with SLE by a group of rheumatology in an autoimmunity referral centre and followed for one year. The new 2019 EULAR/ACR classification criteria were applied to the information collected from the clinical records. Three sets of criteria were compared using Cohen's kappa coefficient and concordance was evaluated

Results: We obtained information for 480 patients, in this analysis were mostly females (96\%). Anti-nuclear antibody (ANA) results were available for $95 \%$ of the patients. According to SLICC classification criteria the diagnosis of SLE was definite in $92 \%$ of patients, $81 \%$ by ACR 1997 and $89 \%$ using ACR/EULAR 2019. The sensibility was $93 \%$ and $97 \%$ for ACR/EULAR 2019 and SLICC 2012, and the specificity was $67 \%$ and $48 \%$ respectively. The concordance analysis between the two sets of criteria showed agreement of $92 \%$ (kappa $0.52 p<0.001$ ) in the whole group.

Conclusion: We found good agreement between SLICC 2012 criteria and EULAR/ACR 2019 classification criteria. In contrast with previous studies, where the new criteria had a sensitivity of $96.1 \%$ and specificity of $93.4 \%$, in our cohort the sensitivity was maintained in $93 \%$ but the specificity decreased to $67 \%$. A possible explanation could be the ANA negativity that was seen in $5 \%$ of the patients and would force to discard patients with false negative results. Despite this, the agreement of the criteria is good and should continue to be applied in our population, without abandoning the expert's clinical criteria.

References:

[1] Aringer M, Costenbader K, Daikh D, et al. 2019 European League against Rheumatism/American College of rheumatology classification criteria for systemic lupus erythematosus. Ann Rheum Dis2019;78:1151-9

[2] Petri M, Orbai A-M, Alarcón GS, et al. Derivation and validation of the systemic lupus international collaborating clinics classification criteria for systemic lupus erythematosus. Arthritis Rheum2012;64:2677-86.

[3] Hochberg MC. Updating the American College of rheumatology revised criteria for the classification of systemic lupus erythematosus. Arthritis Rheum1997;40:1725.

Disclosure of Interests: Sebastian Herrera Speakers bureau: academic conference, Juan camilo Diaz-Coronado: None declared, Deicy Hernandez-Parra: None declared, Yecenia Durango-Durango: None declared, Carolina PerezRios: None declared, Marcela Posada-Velásquez: None declared, Jennifer Rojas-Londoño: None declared, Manuela Vallejo-Patiño: None declared, Katherine Marín: None declared, Carlos Guerrero-Calderón: None declared, Sara jaramillo: None declared, Veronica Usuga-Graciano: None declared, Martha Isabel López-Flórez: None declared, Camilo Restrepo-Raigosa: None declared, Juan Pablo Restrepo-Hincapié: None declared, Catalina Carvajal-Naranjo: None declared, Sarita Restrepo-Upegui: None declared, Ricardo Pineda. Tamayo: None declared

DOI: 10.1136/annrheumdis-2020-eular.6527

\section{THU0270 ONLINE INTERACTION AND FREQUENT SELF- ASSESSMENTS PROMOTED TREAT-TO-TARGET FOR SLE VIA EMPOWERING PATIENTS: A COHORT STUDY FROM CHINA BY SMART SYSTEM OF DISEASE MANAGEMENT (SSDM)}

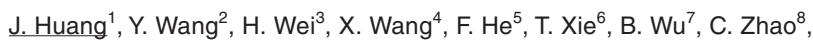
H. Xiao ${ }^{9}$, B. $\mathrm{Wu}^{9}$, Y. $\mathrm{Jia}^{9}, \mathrm{~F} . \mathrm{Xiao}^{9}$, C. Bao ${ }^{10}$ on behalf of SSDM Collaboration Group, China. ${ }^{1}$ The Sixth Affiliated Hospital of Sun Yat-sen University, Guangdong, China; ${ }^{2}$ The First Affiliated Hospital of BaoTou Medical College, Neimenggu, China; ${ }^{3}$ Northern Jiangsu People's Hospital, Jiangsu, China; ${ }^{4}$ Anyang District Hospital, Anyang, China; ${ }^{5}$ Suining Central Hospital, Sichuan, China; ${ }^{6}$ Affiliated Hospital of Guangdong Medical University, Zhanjiang, China; ${ }^{7}$ Chongqing Hospital of Traditional Chinese Medicine, Chongqing, China; ${ }^{8}$ The First Affiliated Hospital of Guangxi Medical University, Nanning, China; ${ }^{9}$ Shanghai Gothic Internet Technology Co., Ltd., Shanghai, China: ${ }^{10}$ Renji Hospital, Shanghai Jiaotong University School of Medicine, Shanghai, China

Background: Treating to target (T2T) is routine in RA, but no comparable standard has been defined for SLE. In 2015, the definition of Lupus Low Disease Activity State (LLDAS) was generated by Asia-Pacific Lupus Collaboration, and the preliminary validation demonstrated its attainment to be associated with improved outcomes in SLE. A SLEDAI-2K score lower than 4 is the main criteria for LLDAS. SSDM is an interactive mobile disease management application, including application systems for both the doctors and patients.

Objectives: To evaluate the patterns of T2T and related influential factors among SLE patients after applying SSDM in real world.

Methods: Patients were trained to master SSDM by healthcare professionals in clinics. The first assessment for SLEDAI-2K was performed as the baseline. Patients were required to perform repeated self-assessments after leaving the clinics. The data is synchronized to the SSDM of authorized rheumatologists. Based on the patients' data, rheumatologists will provide medical advices to the patients.

Results: From July 2015 to Jan 2020, 32,559 SLE patients enrolled in SSDM. The mean age is 36.35 years old and median disease duration is 3.85 years. Among them 1,937 SLE patients from 134 hospitals across China were followed up for more than 12 months, and the demographics were summarized in table 1.

\section{Table 1.}

\begin{tabular}{lcccccccccc}
\hline $\begin{array}{l}\text { BaselinelFinal } \\
\text { follow-up }\end{array}$ & $\mathrm{n}$ & $\%$ & $\mathrm{x}<=4$ & $\begin{array}{c}5<=\mathrm{x} \\
<=9\end{array}$ & $\begin{array}{c}10<=\mathrm{x} \\
<=14\end{array}$ & $\begin{array}{c}15 \\
<=\mathrm{x}\end{array}$ & $\begin{array}{c}\text { < } \\
<<=4\end{array}$ \\
\hline $\mathrm{x}<=4$ & 1040 & $53.69 \%$ & 820 & $78.85 \%$ & 135 & $12.98 \%$ & 50 & $4.81 \%$ & 35 & $3.37 \%$ \\
$5<=\mathrm{x}<=9$ & 357 & $18.43 \%$ & 230 & $64.43 \%$ & 60 & $16.81 \%$ & 32 & $8.96 \%$ & 35 & $9.80 \%$ \\
$10<=\mathrm{x}<=14$ & 222 & $11.46 \%$ & 120 & $54.05 \%$ & 38 & $17.12 \%$ & 40 & $18.02 \%$ & 24 & $10.81 \%$ \\
$15<=\mathrm{x}$ & 318 & $16.42 \%$ & 156 & $49.06 \%$ & 49 & $15.41 \%$ & 47 & $14.78 \%$ & 66 & $20.75 \%$ \\
Total & 1937 & $100 \%$ & 1326 & $68.46 \%$ & 282 & $14.56 \%$ & 169 & $8.72 \%$ & 160 & $8.26 \%$
\end{tabular}

The ratio of T2T achievers was $53.69 \%(1,040 / 1,937)$ at the baseline and improved significantly to $68.46 \%(1,326 / 1,937)$ after a 12 -month follow-up, $p<0.01$. Among T2T achievers at the baseline, $78.85 \%(820 / 1,040)$ maintained T2T, and $21.15 \%(220 / 1,040)$ relapsed. Of patients who didn't achieve T2T at baseline, $56.41 \%(506 / 897)$ of the patients achieve T2T after 12-month follow-up.

The impact of the online interaction and the frequency of self-assessment for SLEDAI-2K on T2T has been analyzed. Compared with 1,475 patients who didn't interact online with their physicians through SSDM, 462 patients with online interaction achieved higher rate of T2T improvement $(19.48 \%$ vs $13.29 \%, p<0.05)$. The more frequent of the self-assessments being performed by patients, the higher improvement of T2T rate will be. The improvement rates of T2T in the subgroups which self-assessed with SSDM by quarterly, bimonthly and monthly were $8.56 \%, 16.14 \%$ and $23.24 \%$ respectively. The improvement rate (y) of T2T was positively correlated with the frequency of self-assessment for SLEDAI-2K(x) independently, $r=0.9998$ (Figure 1)

Conclusion: After proactive disease management via SSDM for more than 12 months, the rate of T2T in SLE patients increased significantly. Online interaction between patients and physicians contributed in promoting T2T improvement rate. The patients who performed more self-assessments through SSDM had higher probability of T2T achievement. SSDM is a valuable tool for long term SLE follow-up through empowering patients. 
References:

Figure 1. The improvement rate of T2T in the subgroups with assessment frequency

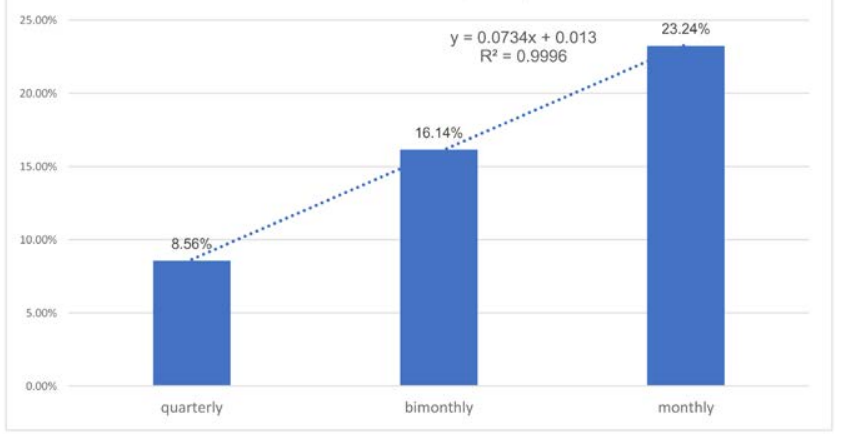

Acknowledgments: SSDM was developed by Shanghai Gothic Internet Technology Co., Ltd.

Disclosure of Interests: None declared

DOI: 10.1136/annrheumdis-2020-eular.1917

\section{THU0271 \\ PERFORMANCE OF THE EULAR/ACR 2019 CLASSIFICATION CRITERIA FOR SYSTEMIC LUPUS ERYTHEMATOSUS IN EARLY DISEASE, ACROSS SEXES AND ETHNICITIES}

S. Johnson ${ }^{1}$, R. Brinks ${ }^{2}$, K. Costenbader ${ }^{3}$, D. Daikh ${ }^{4}$, M. Mosca $^{5}$, R. RamseyGoldman $^{6}$, J. S. Smolen ${ }^{7}$, D. Wofsy ${ }^{4}$, D. Boumpas ${ }^{8}$, D. L. Kamen ${ }^{9}$, D. Jayne ${ }^{10}$, R. Cervera ${ }^{11}$, N. Costedoat-Chalumeau ${ }^{12}$, B. Diamond ${ }^{13}$, D. D. Gladman ${ }^{1}$, B. H. Hahn ${ }^{4}$, F. Hiepe ${ }^{14}$, S. Jacobsen ${ }^{15}$, D. Khanna ${ }^{16}$, K. Lerstrom ${ }^{17}$, E. Massarotti ${ }^{3}$, W. J. Mccune ${ }^{16}$, G. Ruiz-Irastorza ${ }^{18}$, J. Sanchez-Guerrero ${ }^{1}$, M. Schneider ${ }^{2}, M$. B. Urowitz ${ }^{1}$, G. Bertsias ${ }^{19}$, B. F. Hoyer ${ }^{20}$, N. Leuchten ${ }^{21}$, C. Tani ${ }^{5}$, S. Tedeschi ${ }^{3}$, Z. Touma ${ }^{1}$, G. Schmajuk ${ }^{4}$, B. Anic ${ }^{22}$, F. Assan ${ }^{23}$, T. Chan ${ }^{24}$, A. E. Clarke ${ }^{25}$, M. K. Crow ${ }^{26}$, L. Czirják ${ }^{27}$, A. Doria ${ }^{28}$, W. Graninger ${ }^{29}$, B. Halda-Kiss ${ }^{27}$, S. Hasni ${ }^{30}$, P. Izmirly ${ }^{31}$, M. Jung ${ }^{25}$, G. Kumanovics ${ }^{27}$, X. Mariette ${ }^{23}$, I. Padjen ${ }^{22}$, J. M. PegoReigosa $^{32}$, J. Romero-Diaz ${ }^{33}$, I. Rua-Figueroa ${ }^{34}$, R. Seror ${ }^{23}$, G. Stummvoll ${ }^{7}$, Y. Tanaka ${ }^{35}$, M. Tektonidou ${ }^{8}$, C. Vasconcelos ${ }^{36}$, E. Vital ${ }^{37}$, D. J. Wallace ${ }^{38}$, S. Yavuz ${ }^{39}$, P. L. Meroni ${ }^{40}$, M. Fritzler ${ }^{25}$, R. Naden ${ }^{41}$, T. Dörner ${ }^{14}$, M. Aringer ${ }^{21} .{ }^{1}$ University of Toronto, Canada; ${ }^{2}$ Heinrich Heine University, Germany; ${ }^{3}$ Brigham \& Women's Hospital, United States of America; ${ }^{4}$ University of California, United States of America; ${ }^{5}$ Azienda Ospedaliero Universitaria Pisana, Italy; ${ }^{6}$ Northwestern University, United States of America; ${ }^{7}$ University of Vienna, Austria; ${ }^{8}$ University of Athens, Greece: ${ }^{9}$ University of South Carolina, United States of America; ${ }^{10}$ University of Cambridge, United Kingdom; ${ }^{11}$ Hospital Clínic, Spain; ${ }^{12}$ Cochin Hospital, France; ${ }^{13}$ Feinstein Institute, United States of America; ${ }^{14}$ Charité Universitätsmedizin Berlin, Germany; ${ }^{15}$ Rigshospitalet, Denmark; ${ }^{16}$ University of Michigan, United States of America; ${ }^{17}$ Lupus Europe, United Kingdom; ${ }^{18}$ Hospital Universitario Cruces, Spain; ${ }^{19}$ University of Crete, Greece; ${ }^{20}$ University Hospital of Schleswig Holstein, Germany; ${ }^{21}$ University Medical Center Carl Gustav Carus, Germany; ${ }^{22}$ University of Zagreb, Croatia; ${ }^{23}$ Université Paris Sud, France: ${ }^{24}$ University of Hong Kong, Hong Kong (SAR); ${ }^{25}$ University of Calgary, Canada; ${ }^{26}$ Hospital for Special Surgery, United States of America; ${ }^{27}$ University of Pécs, Hungary; ${ }^{28}$ University of Padova, Italy; ${ }^{29}$ University of Graz, Austria; ${ }^{30} \mathrm{NIH}$, United States of America; ${ }^{31}$ New York University, United States of America; ${ }^{32}$ University Hospital of Vigo, Spain; ${ }^{33}$ Instituto Nacional de Ciencias Médicas y Nutrición Salvador Zubirán, Mexico; ${ }^{34}$ Hospital Dr Negrin, Spain: ${ }^{35}$ University of Occupational \& Environmental Health, Japan; ${ }^{36}$ University of Porto, Portugal; ${ }^{37}$ University of Leeds, United Kingdom; ${ }^{38}$ Cedars Sinai, United States of America; ${ }^{39}$ Istanbul Bilim University, Turkey; ${ }^{40}$ Istituto Auxologico Italiano, Italy; ${ }^{41}$ McMaster University, Canada

Background: EULAR/ACR 2019 SLE Classification Criteria were validated in an international cohort.

Objectives: To evaluate performance characteristics of SLE classification systems in sex, race/ethnicity, and disease duration subsets.

Methods: Sensitivity and specificity of the EULAR/ACR 2019, SLICC 2012 and ACR 1982/1997 criteria were evaluated in the validation cohort.

Results: The cohort consisted of female $(n=1098)$, male $(n=172)$, Asian $(n=118)$, Black $(n=68)$, Hispanic $(n=124)$ and White $(n=941)$ patients; and patients with an SLE duration of $1-3$ years $(n=196), 3-5$ years $(n=157)$, and $\geq 5$ years $(n=879)$. Among patients with 1-3 years disease duration, the EULAR/ACR criteria had better sensitivity than the ACR criteria $(97 \%(95 \% \mathrm{Cl} 92-99 \%)$ vs $81 \%(95 \% \mathrm{Cl}$ $72-88 \%$ ). The new criteria performed well in men (sensitivity $93 \%$, specificity $96 \%$ ) and women (sensitivity $97 \%$, specificity $94 \%$ ). The new criteria had better sensitivity than the ACR criteria in White (95\% vs $83 \%$ ), Hispanic (100\% vs $86 \%$ ) and Asian patients ( $97 \%$ vs $77 \%)$.
Conclusion: The EULAR/ACR 2019 criteria perform well in patients with early disease, and across sexes and ethnicities.

Disclosure of Interests: Sindhu Johnson Grant/research support from: Boehringer Ingelheim, Corbus Pharmaceuticals, GlaxoSmithKline, Roche, Merck Bayer, Consultant of: Boehringer Ingelheim, Ikaria, Ralph Brinks: None declared, Karen Costenbader Grant/research support from: Merck, Consultant of: AstraZeneca, David Daikh: None declared, Marta Mosca: None declared, Rosalind Ramsey-Goldman: None declared, Josef S. Smolen Grant/research support from: AbbVie, Eli Lilly, Janssen, Merck Sharp \& Dohme, Pfizer, Roche - grant/research support, Consultant of: AbbVie, Amgen Inc., AstraZeneca, Astro, Celgene Corporation, Celtrion, Eli Lilly, Glaxo, ILTOO, Janssen, Medimmune, Merck Sharp \& Dohme, Novartis, Pfizer, Roche, Samsung, Sanofi, UCB - consultant, Speakers bureau: AbbVie, Amgen Inc., AstraZeneca, Astro, Celgene Corporation, Celtrion, Eli Lilly, Glaxo, ILTOO, Janssen, Medimmune, Merck Sharp \& Dohme, Novartis, Pfizer, Roche, Samsung, Sanofi, UCB - speaker, David Wofsy: None declared, Dimitrios Boumpas Grant/research support from: Unrestricted grant support from various pharmaceutical companies, Diane L Kamen Consultant of: Consulted on SLE survey development for Lilly and consulted on SLE trial protocol development for EMD Serono in 2019, David Jayne Grant/research support from: ChemoCentryx, GSK, Roche/Genentech, Sanofi-Genzyme, Consultant of: Astra-Zeneca, ChemoCentryx, GSK, InflaRx, Takeda, Insmed, Chugai, Boehringer-Ingelheim, Ricard Cervera: None declared, Nathalie Costedoat-Chalumeau Grant/research support from: UCB to my institution, Betty Diamond: None declared, Dafna D Gladman Grant/research support from: AbbVie, Amgen Inc., BMS, Celgene Corporation, Janssen, Novartis, Pfizer, UCB - grant/research support, Consultant of: AbbVie, Amgen Inc., BMS, Celgene Corporation, Janssen, Novartis, Pfizer, UCB - consultant, Bevra H. Hahn Grant/research support from: Janssen Research \& Development, LLC, Falk Hiepe: None declared, Soren Jacobsen: None declared, Dinesh Khanna Shareholder of: Eicos Sciences, Inc./Civi Biopharma, Inc., Grant/ research support from: Dr Khanna was supported by NIH/NIAMS K24AR063120, Consultant of: Acceleron, Actelion, Bayer, Boehringer Ingelheim, Bristol-Myers Squibb, Corbus Pharmaceuticals, Horizon Therapeutic, Galapagos, Roche/ Genentech, GlaxoSmithKline, Mitsubishi Tanabe, Sanofi-Aventis/Genzyme, UCB, Kirsten Lerstrom: None declared, Elena Massarotti: None declared, William Joseph McCune: None declared, Guillermo Ruiz-Irastorza: None declared, Jorge Sanchez-Guerrero: None declared, Matthias Schneider: None declared, Murray B Urowitz: None declared, George Bertsias Grant/research support from: GSK, Consultant of: Novartis, Bimba F. Hoyer: None declared, Nicolai Leuchten: None declared, Chiara Tani: None declared, Sara Tedeschi: None declared, Zah Touma: None declared, Gabriela Schmajuk Grant/research support from: Pfizer, Branimir Anic: None declared, Florence Assan: None declared, Tak Chan: None declared, Ann E Clarke: None declared, Mary K. Crow: None declared, László Czirják Consultant of: Actelion, BI, Roche-Genentech, Lilly, Medac, Novartis, Pfizer, Bayer AG, Andrea Doria Consultant of: GSK, Pfizer, Abbvie, Novartis, Ely Lilly, Speakers bureau: UCB pharma, GSK, Pfizer, Janssen, Abbvie, Novartis, Ely Lilly, BMS, Winfried Graninger: None declared, Bernadett Halda-Kiss: None declared, Sarfaraz Hasni: None declared, Peter Izmirly: None declared, Michelle Jung: None declared, Gabor Kumanovics Consultant of: Boehringer, Teva, Speakers bureau: Roche, Lilly, Novartis, Xavier Mariette: None declared, Ivan Padjen: None declared, Jose M Pego-Reigosa: None declared, Juanita Romero-Diaz Consultant of: Biogen, Iñigo Rua-Figueroa: None declared, Raphaèle Seror Consultant of: BMS, Medimmune, Novartis, Pfizer, GSK, Lilly, Georg Stummvoll: None declared, Yoshiya Tanaka Grant/research support from: Asahi-kasei, Astellas, Mitsubishi-Tanabe, Chugai, Takeda, Sanofi, Bristol-Myers, UCB, Daiichi-Sankyo, Eisai, Pfizer, and Ono, Consultant of: Abbvie, Astellas, Bristol-Myers Squibb, El Lilly, Pfizer, Speakers bureau: Daiichi-Sankyo, Astellas, Chugai, Eli Lilly, Pfizer, AbbVie, YL Biologics, Bristol-Myers, Takeda, Mitsubishi-Tanabe, Novartis, Eisai, Janssen, Sanofi, UCB, and Teijin, Maria Tektonidou Grant/research support from: AbbVie, MSD, Novartis and Pfizer, Consultant of: AbbVie, MSD, Novartis and Pfizer, Carlos Vasconcelos: None declared, Edward Vital Grant/research support from: AstraZeneca, Roche/Genentech, and Sandoz, Consultant of: AstraZeneca, GSK, Roche/Genentech, and Sandoz, Speakers bureau: Becton Dickinson and GSK, Daniel J Wallace: None declared, Sule Yavuz: None declared, Pier Luig Meroni: None declared, Marvin Fritzler: None declared, Raymond Naden: None declared, Thomas Dörner Grant/research support from: Janssen, Novartis, Roche, UCB, Consultant of: Abbvie, Celgene, Eli Lilly, Roche, Janssen, EMD, Speakers bureau: Eli Lilly, Roche, Samsung, Janssen, Martin Aringer Consultant of: Boehringer Ingelheim, Roche, Speakers bureau: Boehringer Ingelheim, Roche DOI: 10.1136/annrheumdis-2020-eular.2324

\section{THU0272 \\ BASEMENT MEMBRANE SEROLOGICAL MARKERS OF COLLAGEN TYPE IV AND LAMININ REMODELING ARE DIFFERENTIALLY EXPRESSED IN SLE}

S. D. Kay ${ }^{1}$, F. Genovese ${ }^{2}$, A. S. Siebuhr ${ }^{2}$, M. Karsdal ${ }^{2}$, A. Voss ${ }^{1}$, P. Junker ${ }^{3}$ 'Odense University Hospital, Department of Rheumatology, Odense, Denmark; 